\title{
Model Jaringan Saraf Tiruan Backpropagation Untuk Meningkatkan Penguasaan Mahasiswa Pada Matakuliah Algoritma Dan Pemrograman
}

\author{
Muhammad Ridwan Lubis \\ AMIK Tunas Bangsa Pematangsiantar \\ ridwanlubis@amiktunasbangsa.ac.id
}

Cara Sitasi: Lubis, M. R. (2019, Maret). Model Jaringan Saraf Tiruan Backpropagation Untuk Meningkatkan Penguasaan Mahasiswa Pada Matakuliah Algoritma Dan Pemrograman. (S. Dalis, Ed.) Paradigma - Jurnal Komputer dan Informatika, 21(1), 91-96. doi:10.31294/p.v21i1.5079

\begin{abstract}
Untuk meningkatkan keterampilan mahasiswa dalam belajar merupakan harapan setiap dosen. Dalam program studi dasar komputer dibutuhkan master pemrograman. Algoritma dan Pemrograman adalah program dasar yang harus dipelajari. Sementara itu, menggunakan metode backpropogation yang merupakan bagian dari Jaringan Syaraf Tiruan akan menguji dan melatih data dengan menggunakan algoritma backpropogation untuk meningkatkan kemampuan mahasiswa untuk memahami matakuliah algortima dan pemrograman. Hasil yang dapat dianalisis tentang hasil jika outputnya mendekati target maka proses pelatihan dapat diselesaikan. Selanjutnya, Kesalahan rata-rata dapat dihitung dari hasil pelatihan yang telah dilakukan. Jika hasilnya belum tercapai maka metode backpropagation selalu melakukan iterasi dengan melakukan perubahan bobot hingga hasil maksimal dan dapat untuk mendapatkan hasil yang menjadi target dengan metode backpropagation yang digunakan.
\end{abstract}

Keywords: Agoritma dan pemrograman, jaringan saraf tiruan, backpropagation

\section{PENDAHULUAN}

Dalam upaya meningkatkan kemampuan mahasiswa untuk memahami setiap matakuliah tidak terlepas dari usaha perguruan tinggi memberlakukan kebijaksanaan-kebijaksanaan dari peraturan kementrian pendidikan. Salah satu kebijakan yang sudah dilakukan oleh kampus dalam upaya peningkatan kemampuan mahasiswa dalam menguasai matakuliah khusus yang ditetapkan dalam satu kurikulum adalah dengan memanfaatkan media informasi dalam setiap kepentingan, baik berupa tugas yang diberikan oleh dosen pengampuh dan rasa keingintahuan mahasiswa tersebut terhadap tugas yang diberikan. Selain itu, ada juga mahasiswa yang menganggap sebuah tugas yang diberikan setiap dosen merupakan beban tambahan mahasiswa yang akhirnya karena merasa terbebani dengan tugas tersebut bisa jadi tidak mengerjakannya.

Untuk menumbuhkan kemauan mahasiswa dalam memahami setiap matakuliah, penulis merujuk kepada penelitian yang sudah dilakukan para peneliti sebelumnya, diantaranya faktor-faktor yang berkontribusi pada prestasi belajar mahasiswa Fakultas Teknologi Informasi (FTI) dalam mempelajari matakuliah Programming (Mildawati, Faried, \& Novita, n.d.) , Peningkatan akurasi klasifikasi penguasaan materi bahan ajar menggunakan jaringan saraf tiruan dan algortima genetika. Dari penelitian tersebut ada beberapa faktor yang mempengaruhi prestasi mahasiswa diantaranya minat, motivasi, bakat, kecerdasan, faktor biologis, dosen, kurikulum, sarana dan prasarana serta lingkungan sosial. Penguasaan dosen dalam berkomunikasi, penguasaan materi bahan ajar juga mempengaruhi pemahaman mahasiswa. Penggunaan GA dalam menentukan nilai parameter JST mampu meningkatkan akurasi pengukuran dari 85.36\% menjadi 85.73\% (Somantri et al., 2017).

Dari beberapa penelitian yang sudah dilakukan diatas, meningkatkan mutu dan kualitas mahasiswa merupakan kewajiban perguruan tinggi yang sudah jelas merupakan visi dan misi sebuah program

studi dalam menghasilkan lulusan yang menguasai ilmu pengetahuan yang beretika dan profesional. Berdasarkan permasalahan tersebut perlu adanya metode yang tepat dalam meningkatkan kemampuan mahasiswa dalam memahami setiap matakuliah yang sudah ditetapkan dalam kurikulum.

Dari permasalahan diatas, penulis merumuskan masalah yang berkaitan dengan penelitian yang akan dilakukan penulis adalah metode yang tepat untuk meningkatkan pemahaman mahasiswa dalam setiap matakuliah.

1. Penulis menggunakan metode optimasi untuk meningkatkan pemahaman mahasiswa

2. Penulis menggunakan Metode Neural Network backropgation untuk proses komputasi.

3. Penulis hanya melakukan penelitian terhadap tingkat pemahaman mahasiswa dalam 
memahami matakuliah algoritma dan pemrograman.

\section{METODOLOGI PENELITIAN}

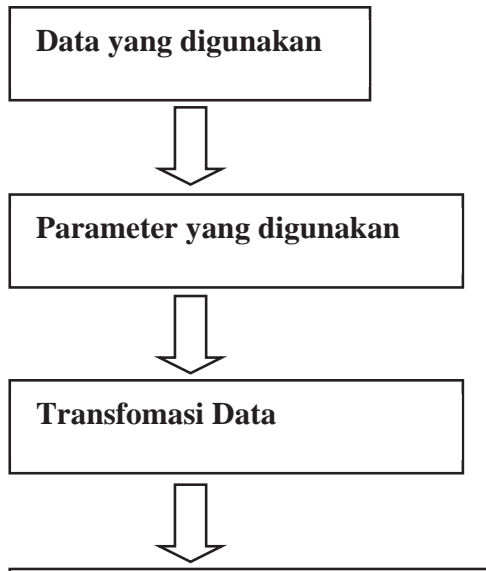

Analisis Menggunakan Model Backpropagation

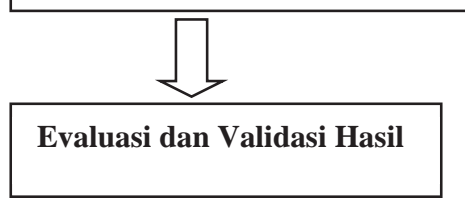

Gambar 1. Tahapan Penelitian

Pada rancangan proses, ada beberapa tahapan yang penulis konsep untuk mendapatkan hasil prediksi. Berikut ini penjelasan dari beberapa tahapan pada rancangan proses :

a) Data yang digunakan

Data yang digunakan pada peneltian ini adalah data mahasiswa semester 1 dan 2 tahun akademik 2017-2018 yang mengambil matakuliah algoritma dan pemrograman I dan Algoritma Pemrograman II di AMIK Tunas Bangsa Pematangsiantar.

b) Parameter yang digunakan

Parameter yang digunakan dalam penelitian ini adalah : minat, motivasi, bakat, kecerdasan, faktor biologis, dosen, kurikulum, sarana dan prasarana serta lingkungan sosial.

c) Transformasi Data

Pada tahap tranformasi data dilakukan proses komputasi data dengan menggunakan Persamaan 1

$$
\mathrm{X}^{1}=\frac{(X-X \min )(b-\alpha)}{(X \max -X \min )}+\alpha
$$

Keterangan :

$\mathrm{X}^{1}$ adalah Nilai Transformasi , $\mathrm{X}$ adalah nilai asli Xmin adalah nilai minimal pada satu kolom data, XMax adalah nilai maksimal pada satu kolom data, b, $\alpha$ adalah nilai atas dan nilai bawah (antara 0,1..0,9) (Lubis, Studi, \& Informatika, 2017).

Proses transformasi dilakukan dengan ketentuan menggunakan parameter yang sudah ditentukan dan ditampilkan pada Tabel 1 berikut :

Tabel 1. Hasil Transformasi Data Penelitian

\begin{tabular}{|c|c|c|c|c|c|c|c|}
\hline $\mathrm{X} 1$ & $\mathrm{X} 2$ & X3 & $\mathrm{X} 4$ & X5 & X6 & X7 & X8 \\
\hline 0,50 & 0,10 & 0,19 & 0,10 & 0,10 & 0,10 & 0,10 & 0,10 \\
\hline 0 & 0 & 5 & 0 & 0 & 0 & 0 & 0 \\
\hline 0,90 & 0,90 & 0,90 & 0,90 & 0,90 & 0,90 & 0,90 & 0,90 \\
\hline 0 & 0 & 0 & 0 & 0 & 0 & 0 & 0 \\
\hline 0,90 & 0,90 & 0,90 & 0,90 & 0,90 & 0,90 & 0,90 & 0,90 \\
\hline 0 & 0 & 0 & 0 & 0 & 0 & 0 & 0 \\
\hline 0,90 & 0,90 & 0,29 & 0,90 & 0,90 & 0,90 & 0,90 & 0,90 \\
\hline 0 & 0 & 0 & 0 & 0 & 0 & 0 & 0 \\
\hline 0,70 & 0,90 & 0,24 & 0,50 & 0,50 & 0,50 & 0,50 & 0,50 \\
\hline 0 & 0 & 2 & 0 & 0 & 0 & 0 & 0 \\
\hline 0,50 & 0,90 & 0,19 & 0,90 & 0,90 & 0,90 & 0,90 & 0,90 \\
\hline 0 & 0 & 5 & 0 & 0 & 0 & 0 & 0 \\
\hline 0,90 & 0,90 & 0,90 & 0,90 & 0,90 & 0,90 & 0,90 & 0,90 \\
\hline 0 & 0 & 0 & 0 & 0 & 0 & 0 & 0 \\
\hline 0,90 & 0,90 & 0,90 & 0,90 & 0,90 & 0,90 & 0,90 & 0,90 \\
\hline 0 & 0 & 0 & 0 & 0 & 0 & 0 & 0 \\
\hline 0,90 & 0,90 & 0,90 & 0,90 & 0,90 & 0,90 & 0,90 & 0,90 \\
\hline 0 & 0 & 0 & 0 & 0 & 0 & 0 & 0 \\
\hline 0,81 & 0,90 & 0,26 & 0,90 & 0,90 & 0,90 & 0,90 & 0,90 \\
\hline 4 & 0 & 9 & 0 & 0 & 0 & 0 & 0 \\
\hline 0,30 & 0,90 & 0,14 & 0,90 & 0,90 & 0,90 & 0,90 & 0,90 \\
\hline 0 & 0 & 7 & 0 & 0 & 0 & 0 & 0 \\
\hline 0,10 & 0,90 & 0,10 & 0,90 & 0,90 & 0,90 & 0,90 & 0,90 \\
\hline 0 & 0 & 0 & 0 & 0 & 0 & 0 & 0 \\
\hline 0,90 & 0,90 & 0,90 & 0,90 & 0,90 & 0,90 & 0,90 & 0,90 \\
\hline 0 & 0 & 0 & 0 & 0 & 0 & 0 & 0 \\
\hline 0,90 & 0,90 & 0,90 & 0,90 & 0,90 & 0,90 & 0,90 & 0,90 \\
\hline 0 & 0 & 0 & 0 & 0 & 0 & 0 & 0 \\
\hline 0,90 & 0,90 & 0,90 & 0,90 & 0,90 & 0,90 & 0,90 & 0,90 \\
\hline 0 & 0 & 0 & 0 & 0 & 0 & 0 & 0 \\
\hline 0,90 & 0,90 & 0,90 & 0,90 & 0,90 & 0,90 & 0,90 & 0,90 \\
\hline 0 & 0 & 0 & 0 & 0 & 0 & 0 & 0 \\
\hline 0,90 & 0,90 & 0,90 & 0,90 & 0,90 & 0,90 & 0,90 & 0,90 \\
\hline 0 & 0 & 0 & 0 & 0 & 0 & 0 & 0 \\
\hline 0,70 & 0,90 & 0,24 & 0,90 & 0,90 & 0,90 & 0,90 & 0,90 \\
\hline 0 & 0 & 2 & 0 & 0 & 0 & 0 & 0 \\
\hline 0,90 & 0,90 & 0,90 & 0,90 & 0,90 & 0,90 & 0,90 & 0,90 \\
\hline 0 & 0 & 0 & 0 & 0 & 0 & 0 & 0 \\
\hline
\end{tabular}

d) Analisis Menggunakan Model Backpropagation

Seperti yang sudah dijelaskan pada Bab 1 mengenai Metode yang digunakan untuk analisis jaringan saraf tiruan, penulis menerapkan metode Neural Network model backpropagation.

untuk mendefinisikan nilai awal seperti nilai input data (weight), bias dan nilai output (y) yang diharapkan. Tahap awal pembelajaran ditandai dengan menentukan arsitektur neural network yang terdiri dari 8 (delapan) input,1 (satu) hidden layer dengan jumlah $n$ neuron dan 1(satu) output (Lubis, Studi, Akuntansi, \& Penelitian, n.d.).

Untuk memprediksi hasil dengan metode JST, algoritma yang digunakan adalah sebagai berikut : 
a. Menentukan jenis arsitektur Back Propagation dan menentukan jumlah neuron pada hidden layer. Untuk menentukan jumlah neuron pada hidden layer berada diantara jumlah neuron pada input layer dan output layer.

b. Inisialiasi bobot dan bias awal secara random antara 0 sampai dengan 1 .

Tabel 2. Inisialisasi Bobot pada hidden layer

\begin{tabular}{|l|l|l|}
\hline & $\mathbf{Z 1}$ & $\mathbf{Z 2}$ \\
\hline $\mathbf{X 1}$ & 0,1 & 0,3 \\
\hline $\mathbf{X 2}$ & 0,5 & 0,1 \\
\hline $\mathbf{X 3}$ & $-0,2$ & 0,1 \\
\hline $\mathbf{X} 4$ & 0,1 & $-0,2$ \\
\hline $\mathbf{X 5}$ & 0,3 & 0,1 \\
\hline $\mathbf{X 6}$ & $-0,4$ & 0,4 \\
\hline $\mathbf{X 7}$ & 0,3 & 0,5 \\
\hline $\mathbf{X 8}$ & 0,2 & 0,2 \\
\hline
\end{tabular}

Tabel 3. Inisialisasi Bobot pada output layer

\begin{tabular}{|l|l|}
\hline & Z3 \\
\hline Z1 & $-0,1$ \\
\hline Z2 & $-0,5$ \\
\hline
\end{tabular}

c. Menyebarkan data pada input layer menuju hidden layer dengan mengalikan setiap data pada unit neuron input layer dengan bobot yang menghubungkan antar neuron, hasil perkalian tersebut dijumlahkan lalu ditambahkan dengan biasnya.

Znet1 $=(\mathrm{x} 1 . \mathrm{w} 1)+(\mathrm{x} 2 . \mathrm{w} 2)+(\mathrm{x} 3 . \mathrm{w} 3)+(\mathrm{x} 4 . \mathrm{w} 4)$ $+(\mathrm{x} 5 . \mathrm{w} 5)+(\mathrm{x} 6 . \mathrm{w} 6)+(\mathrm{x} 7 . \mathrm{w} 7)+(\mathrm{x} 8 . \mathrm{w} 8)$ $(0,5.0,1)+(0,1.0,5)+(0,19.0,2)+(0,1.0,1)+(0$ $, 1.0,3)+(0,1 .-0,4)+(0,1.0,3)$ $+(0,1.0,2)$

$$
=0,111017
$$

d. Masing-masing sinyal diaktifkan dengan fungsi aktifasi sigmoid.

e. Sinyal yang telah diaktifkan dikirim menuju output layer dengan cara mengalikan sinyal pada hidden layer dengan bobot yang menghubungkan antar neuron ke output layer. Hasil perkalian tersebut dijumlahkan.

f. Aktivasi dengan sigmoid function

g. Mengitung Error pada unit keluaran.

h. Jika hasil belum mencapai target, lakukan perubahan nilai bobot pada bobot pertama. Selanjutnya lakukan langkah (b-g) sehingga output mencapai atau mendekati target.

\section{HASIL DAN PEMBAHASAN}

Berikut ini adalah hasil dari beberapa model pengujian arsitektur dengan menggunakan metode backpropagation dengan pola 8-4-1, 8-5-1 dan pola 8-6-3-1. Hasil digambarkan dalam bentuk grafik dengan target 0.9 dan learning rate 0.1 da jumlah iterasi maksimum.

1. Pengujian dengan Arsitektur 8-4-1

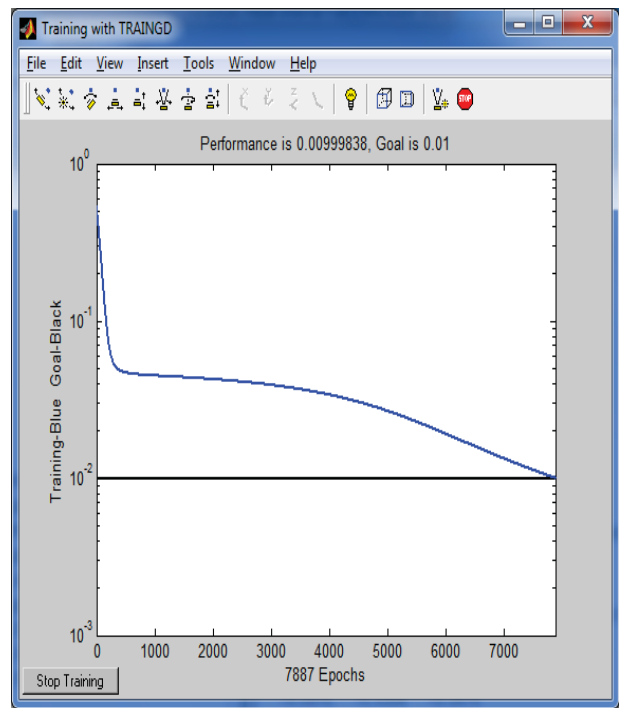

Gambar 2. Hasil Model 8-4-1

Gambar diatas merupakan hasil dari arsitektur dengan model 8-4-1. Dengan nilai target 0.9 dan learning rate 0.01 menghasilkan output terbaik dengan jumlah iterasi sebanyak 7887 epochs.

2. Pengujian dengan Arsitektur 8-5-1

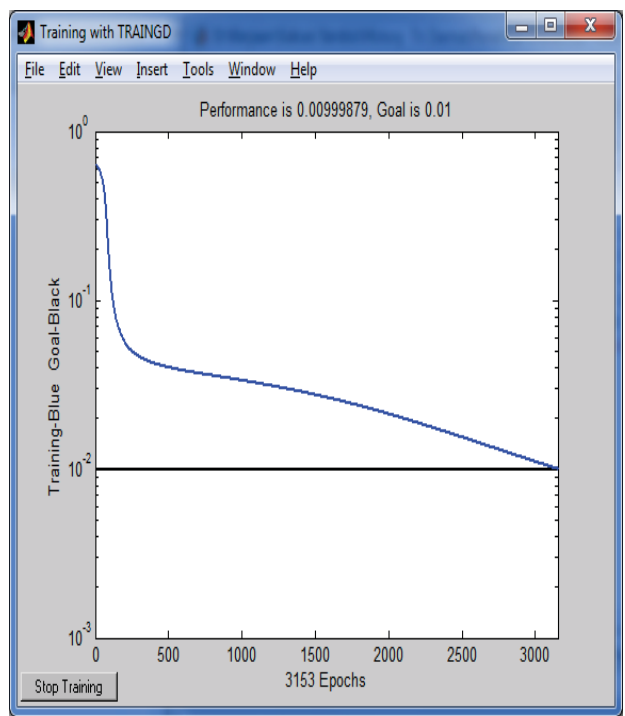

Gambar 3. Hasil Model 8-5-1 
Gambar diatas merupakan hasil dari arsitektur dengan model 8-5-1. Dengan nilai target 0.9 dan learning rate 0.01 menghasilkan output terbaik dengan jumlah iterasi sebanyak 3153 epochs.

3. Pengujian dengan Arsitektur 8-6-3-1

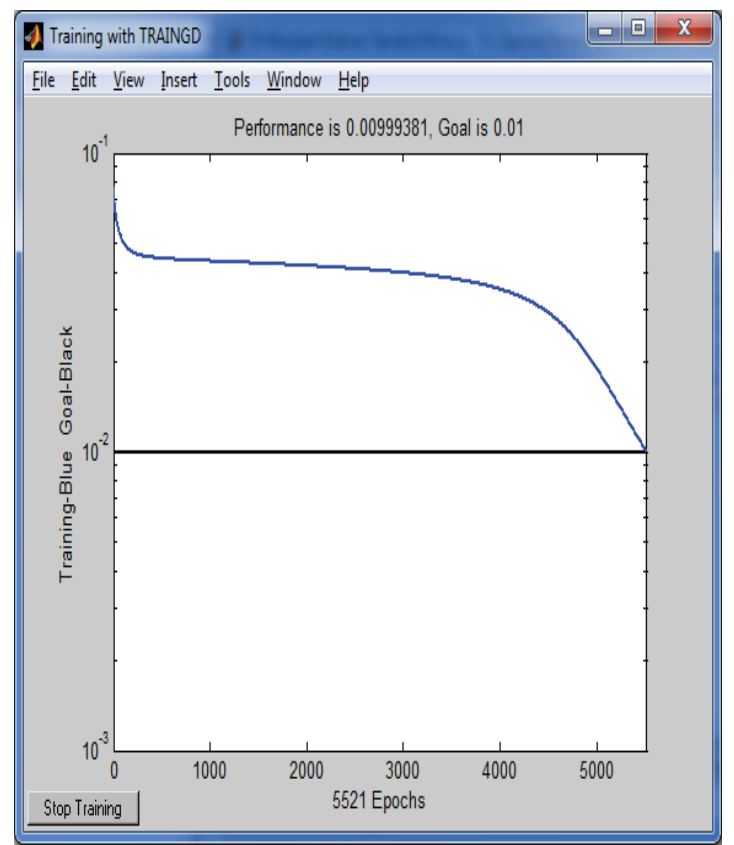

Gambar 4. Hasil Model 8-6-3-1

Gambar diatas merupakan hasil dari arsitektur dengan model 8-6-3-1. Dengan nilai target 0.9 dan learning rate 0.01 menghasilkan output terbaik dengan jumlah iterasi sebanyak 5521 epochs.

\section{KESIMPULAN}

Tabel 4. Hasil Pengujian dengan beberapa model arsitektur metode backpropagation

\begin{tabular}{|l|l|l|}
\hline No & $\begin{array}{l}\text { Arsitektur } \\
\text { Model }\end{array}$ & $\begin{array}{l}\text { Jumlah } \\
\text { Iterasi }\end{array}$ \\
\hline 1 & $8-4-1$ & 7887 \\
\hline 2 & $8-5-1$ & 3153 \\
\hline 5 & $8-6-3-1$ & 5521 \\
\hline
\end{tabular}

Dari tabel diatas model terbaik yang dihasilkan oleh pola 8-5-1 dengan jumlah iterasi 3153 epochs dengan target 0,9 dan learning rate maksimum 0.1.

Selanjutnya penulis akan melakukan pengujian dengan model optimasi untuk mendapatkan hasil terbaik.

\section{REFERENSI}

Lubis, M. R., Studi, P., Akuntansi, K., \& Penelitian, L. B. (n.d.). Analisis jaringan saraf tiruan back propgation untuk peningkatan akurasi prediksi hasil pertandingan sepakbola.

Lubis, M. R., Studi, P., \& Informatika, M. (2017). METODE HYBRID PARTICLE SWARM OPTIMIZATION - NEURAL NETWORK BACKPROPAGATION UNTUK PREDIKSI HASIL PERTANDINGAN SEPAK BOLA, (1), 71-83.

Mildawati, M., Faried, I., \& Novita, A. (n.d.). B41 Jurnal ticom.pdf.

Somantri, O., Wiyono, S., Menggunakan, A., Syaraf, J., Dan, T., Genetika, A., \& Teknologi, J. (2017). Peningkatan Akurasi Klasifikasi Tingkat Penguasaan Materi Bahan Ajar Menggunakan Jaringan Syaraf Tiruan Dan Algoritma Genetika, 5(September), 147-152. https://doi.org/10.14710/jtsiskom.5.4.2017.147 $-152$

\section{PROFIL PENULIS}

Penulis saat ini adalah dosen tetap di salah satu Perguruan Tinggi di Pematangsiantar (AMIK Tunas Bangsa Pematangsiantar) 